\title{
Diabetes insipidus and panhypopituitarism as a first presentation of silent adenocarcinoma of lung: a case report and literature review
}

Sirinart Sirinvaravong ${ }^{1 *}$ (D) Peeradon Vibhatavata ${ }^{1}$, Paweena Chunharojrith ${ }^{1}$, Pornsuk Cheunsuchon ${ }^{2}$ and Sutin Sriussadaporn ${ }^{1}$

\begin{abstract}
Background: Pituitary metastasis is a rare condition with a poor prognosis. Very few patients with pituitary metastasis are symptomatic. It is often associated with presence of co-existing metastases to other organs. Isolated pituitary metastasis as the first presentation of primary malignancy is uncommon.

Case presentation: A 72-year-old woman presented with a 2-month history of polyuria, increasing thirst and unexplained weight loss. Esophagogastroduodenoscopy (EGD) was scheduled as part of the investigation. She was kept nil per os for $10 \mathrm{~h}$ prior to EGD, after which she developed alteration of consciousness. Further investigation revealed hypernatremia with sodium level of $161 \mathrm{mmol} / \mathrm{L}$ and low urine osmolality of $62 \mathrm{mOsm} / \mathrm{kg}$. Her urine output was $300 \mathrm{~mL}$ per hour. Diabetes insipidus (DI) was diagnosed based on evidence of polyuria, hypernatremia, and low urine osmolality. Her urine output decreased and urine osmolality increased to $570 \mathrm{mOsm} / \mathrm{kg}$ in response to subcutaneous desmopressin acetate, confirming central DI. Pituitary magnetic resonance imaging showed a heterogeneous gadolinium enhancing lesion at the sellar and suprasellar regions, measuring $2.4 \times 2.6 \times 3.9 \mathrm{~cm}$ compressing both the hypothalamus bilaterally and the inferior aspect of optic chiasm as well as displacing the residual pituitary gland anteriorly. The posterior pituitary bright spot was absent. These MRI findings suggested pituitary macroadenoma. There were also multiple small gadolinium-enhancing lesions up to $0.7 \mathrm{~cm}$ in size with adjacent vasogenic brain edema at the subcortical and subpial regions of the left frontal and parietal areas, raising the concern of brain metastases. Pituitary hormonal evaluation was consistent with panhypopituitarism. Histopathological and immunohistochemical studies of the pituitary tissue revealed an adenocarcinoma, originating from the lung. Computed tomography of the chest and abdomen was subsequently performed, showing a $2.2-\mathrm{cm}$ soft tissue mass at the proximal part of right bronchus. There was no evidence of distant metastases elsewhere. The final diagnosis was adenocarcinoma of the lung with pituitary metastasis manifesting as panhypopituitarism and central DI. Palliative care along with hormonal replacement therapy was offered to the patient. She died 4 months after diagnosis.
\end{abstract}

Conclusion: Diagnosis of pituitary metastasis is challenging, especially in patients with previously undiagnosed primary cancer. It should be considered in the elderly patients presenting with new-onset central DI with or without anterior pituitary dysfunction.

Keywords: Pituitary metastasis, Diabetes insipidus, Panhypopituitarism, Adenocarcinoma of lung

\footnotetext{
* Correspondence: sirinart.sir@mahidol.ac.th

'Division of Endocrinology and Metabolism, Department of Medicine, Faculty

of Medicine Siriraj Hospital, Mahidol University, Bangkok, Thailand

Full list of author information is available at the end of the article
}

(c) The Author(s). 2019 Open Access This article is distributed under the terms of the Creative Commons Attribution 4.0 International License (http://creativecommons.org/licenses/by/4.0/), which permits unrestricted use, distribution, and reproduction in any medium, provided you give appropriate credit to the original author(s) and the source, provide a link to the Creative Commons license, and indicate if changes were made. The Creative Commons Public Domain Dedication waiver (http://creativecommons.org/publicdomain/zero/1.0/) applies to the data made available in this article, unless otherwise stated. 


\section{Background}

Metastasis to pituitary gland is a rare situation in clinical practice with a poor prognosis. The prevalence of metastatic pituitary tumors was approximately $1 \%$ among all pituitary tumor resections [1] and 1 to $3.6 \%$ among post-mortem studies [2]. Most of them were asymptomatic and were typically detected incidentally on imaging or at autopsy [3]. One series found that only $7 \%$ of patients with pituitary metastases were symptomatic [4]. Symptomatic pituitary metastasis as the first presentation of primary tumor is uncommon.

Pituitary metastasis is often associated with the presence of multiple additional metastatic sites, especially in bones $[5,6]$. Isolated pituitary metastasis is rare [7-15], and its clinical presentations, pituitary hormonal profiles, and radiological imaging features mimic those of the more common primary pituitary tumors [16]. These characteristics may lead to misdiagnosis and delayed treatment, especially in individuals without a known pre-existing malignancy. Here, we report a rare case of isolated pituitary metastasis from adenocarcinoma of the lung first presenting as central diabetes insipidus and panhypopituitarism without known evidence of the primary malignancy. A literature review was performed. A search of the literature was performed on the PubMed and Ovid Medline databases. The initial search string used was "Pituitary AND Metastas." References cited in the articles identified by our original search were also assessed for relevance. Most of the papers identified were case studies and case series; those in languages other than English were excluded.

\section{Case presentation}

A 72-year-old woman with a 5-pack-year smoking history presented with drowsiness after esophagogastroduodenoscopy (EGD). Her past medical history was remarkable for community-acquired pneumonia at right middle lung
(Fig. 1a) 3 months prior, from which she made a full recovery following antibiotic therapy. She had a 2-month history of polyuria, polydipsia, nocturia, lightheadedness upon standing up quickly, fatigue, loss of appetite, and 15 $\mathrm{kg}$ of weight loss from a baseline weight of $60 \mathrm{~kg}$. She had no fever, cough, dyspnea, hemoptysis, chest pain, or night sweats. She presented to the outpatient unit, and the investigation at that time showed a fasting plasma glucose level of $100 \mathrm{mg} / \mathrm{dL}(5.5 \mathrm{mmol} / \mathrm{L})$ and an HbA1c of $4.8 \%$. Thyroid function tests revealed a normal serum triiodothyronine (T3) level of $2 \mathrm{nmol} / \mathrm{L}$ (reference range 1.23$3.07 \mathrm{nmol} / \mathrm{L}$ ), a low free thyroxine (FT4) level of 3.86 $\mathrm{pmol} / \mathrm{L}$ (reference range 11.97-21.88 pmol/L), and a suppressed thyroid stimulating hormone (TSH) level of 0.06 $\mathrm{mIU} / \mathrm{L}$ (reference range $0.27-4.0 \mathrm{mIU} / \mathrm{L}$ ). A chest $\mathrm{x}$-ray showed minimal infiltration at medial aspect of right lower lung, which had decreased compared with a previous chest $\mathrm{x}$-ray (Fig. 1b).

The patient underwent EGD 2 months after the outpatient visit. She was kept nil per os for $10 \mathrm{~h}$ prior to the procedure. The EGD findings were mild non-erosive antral gastritis. After EGD, she developed nausea, vomiting, and drowsiness. Physical examination revealed a body temperature of $37^{\circ} \mathrm{C}$, a blood pressure of $100 / 57 \mathrm{mmHg}$, a pulse rate of $90 / \mathrm{min}$, and a respiratory rate of $16 / \mathrm{min}$. She was $44.5 \mathrm{~kg}$ in body weight, was $148 \mathrm{~cm}$ in height, and had a body mass index of $20.3 \mathrm{~kg} / \mathrm{m}^{2}$. She had flat neck veins, a normal thyroid gland without nodules, normal breath sounds, no abnormal palpable masses, no hepatosplenomegaly, no breast masses, and no superficial lymphadenopathy. Neurological examination was remarkable for bitemporal hemianopia evaluated by confrontation test.

She was immediately admitted to the hospital because of the altered mental status. At the first hour after admission, she had polyuria with a urine output of 300

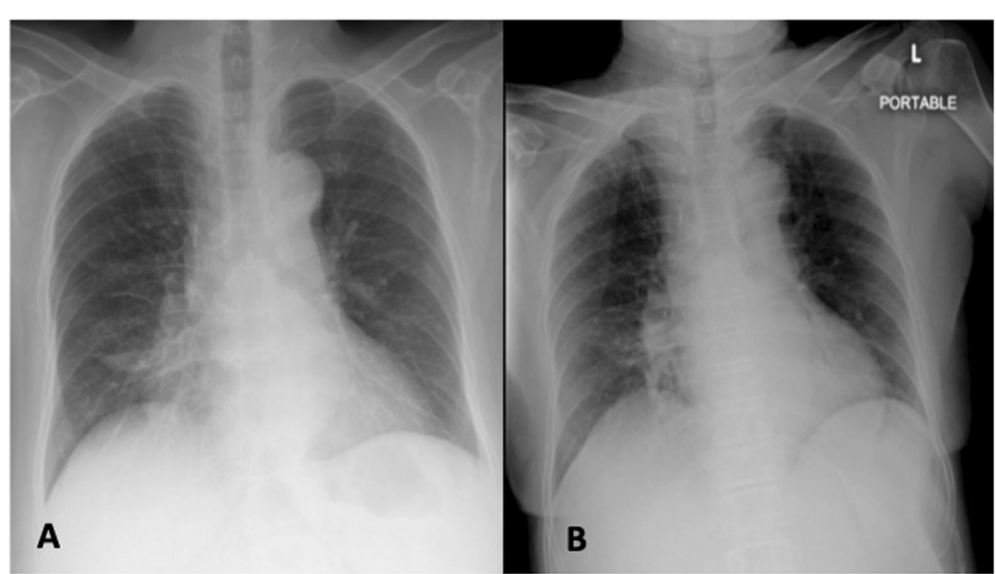

Fig. 1 Chest radiograph 3 months prior to admission showing right middle lobe pneumonia (a) and on admission showing minimal infiltration at medial aspect of right lower lung (b) 
$\mathrm{mL} /$ hour $(6.7 \mathrm{~mL} / \mathrm{kg} /$ hour $)$. Laboratory tests showed a serum sodium level of $160 \mathrm{mmol} / \mathrm{L}$; a potassium level of $3.9 \mathrm{mmol} / \mathrm{L}$; a chloride level of $125 \mathrm{mmol} / \mathrm{L}$; a bicarbonate level of $24 \mathrm{mmol} / \mathrm{L}$; a creatinine level of $1.4 \mathrm{mg} / \mathrm{dL}$. Serum osmolality was $325 \mathrm{mOsm} / \mathrm{kg}$. Her urine specific gravity was 1.002 without proteinuria or glucosuria. Urine osmolality was $62 \mathrm{mOsm} / \mathrm{kg}$. Diabetes insipidus was diagnosed based on evidence of polyuria along with hypernatremia and low urine osmolality. Desmopressin acetate (DDAVP) 1 microgram was given by subcutaneous injection. One hour later, her urine output decreased to $70 \mathrm{~mL} /$ hour, and urine osmolarity increased to 570 $\mathrm{mOsm} / \mathrm{kg}$. Based on decreasing urine output and a more than $50 \%$ increase in urine osmolality in response to DDAVP, a diagnosis of central diabetes insipidus was made.

Given the diagnosis of central diabetes insipidus, further investigations including magnetic resonance imaging (MRI) of the pituitary gland and evaluation of the anterior pituitary hormones were performed. Pituitary MRI demonstrated a heterogeneous high signal intensity (SI) lesion in T1weighted (T1W) imaging, which also appeared as a low SI lesion in T2-weighted (T2W) imaging with heterogeneous gadolinium enhancement at the sellar and suprasellar region, measuring $2.4 \times 2.6 \times 3.9 \mathrm{~cm}$. The lesion was compressing the hypothalamus bilaterally and the inferior aspect of optic chiasm with increased SI in T2W imaging at the right optic nerve and bilateral optic tracts. It was also anteriorly displacing the residual pituitary gland. The pituitary stalk could not be identified, and the bright spot of posterior lobe was absent. These MRI findings suggested pituitary macroadenoma with hemorrhage (Fig. 2). The bony skull showed a normal appearance without lytic lesion. There were also multiple small gadolinium-enhancing lesions up to $0.7 \mathrm{~cm}$ in size with adjacent vasogenic brain edema at subcortical and subpial regions of the left frontal and parietal areas; therefore, multiple stages of cysticercosis and brain metastases were included in the differential diagnosis (Fig. 3).

Pituitary hormonal profiles (Table 1) showed inappropriately low gonadotropins levels, a low plasma adrenocorticotropic hormone (ACTH) level, and a low morning serum cortisol level that did not respond to cosyntropin stimulation, indicating secondary adrenal insufficiency. Serum prolactin level was mildly elevated, but no further increase was seen in a diluted sample. Hyperprolactinemia was suspected to be caused by stalk interruption. Thyroid function tests performed 2 months prior to admission showed a low free T4 level of $3.86 \mathrm{pmol} / \mathrm{L}$ and a low TSH level of $0.06 \mathrm{mIU} / \mathrm{L}$, suggesting central hypothyroidism. On admission, serum free T4 level had decreased to $2.32 \mathrm{pmol} / \mathrm{L}$ with an unexpectedly elevated TSH level of $19.07 \mathrm{mIU} / \mathrm{L}$. A low IGF-1 level in combination with deficiency of more than two pituitary hormones was highly indicative of growth hormone deficiency.

The patient underwent craniotomy for tumor removal. Intraoperative findings showed one grey-purplish firm mass at the sellar and retrochiasmatic regions with some necrosis and hemorrhage. The tumor was partially removed. A histopathological study revealed adenocarcinoma with the immunohistochemical staining positive for cytokeratin-7 and thyroid transcription factor-1 (TTF-1) but negative for cytokeratin-20, CDX-2 and GFAP (Fig. 4). These findings were consistent with metastatic adenocarcinoma originating from the lung.

To identify the primary adenocarcinoma of the lung, a CT scan of the chest was performed which revealed a

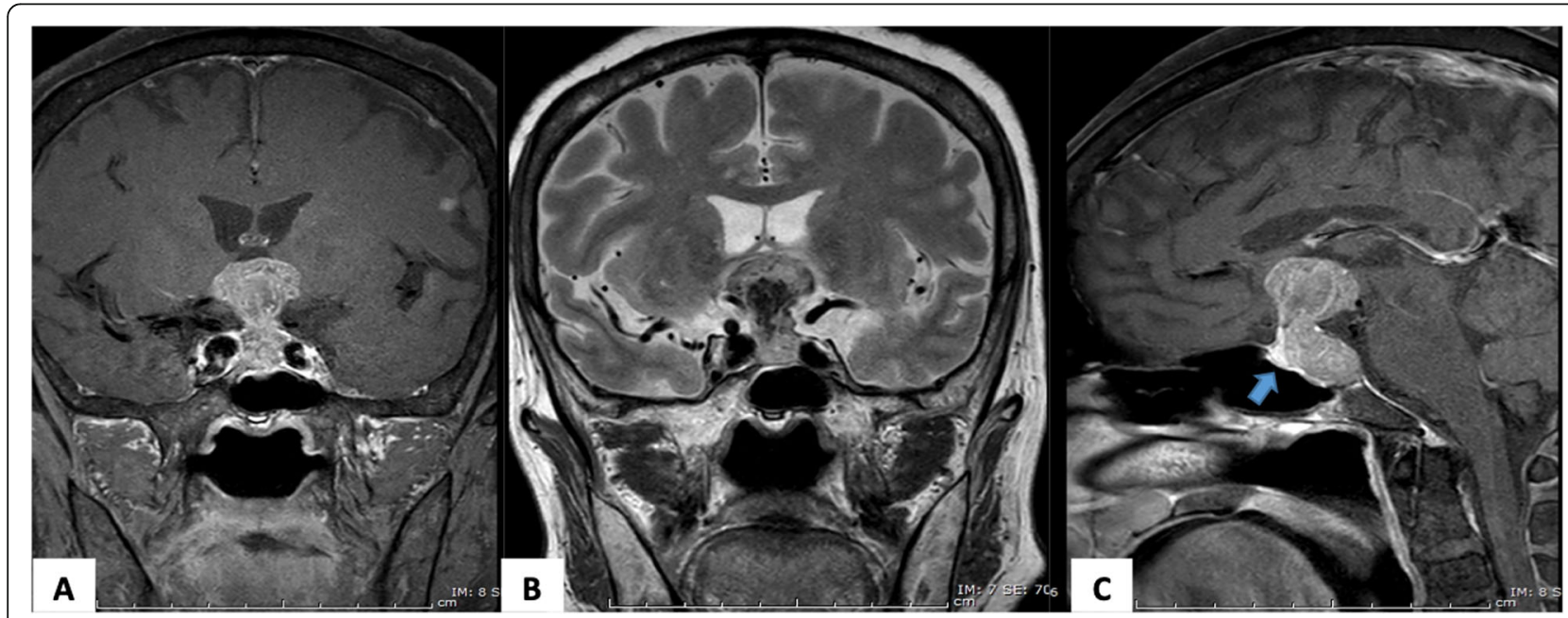

Fig. 2 Pituitary MRI with gadolinium contrast. Coronal T1W (a), coronal T2W (b), sagittal T1W (c) images showing a heterogeneous enhancing lesion at sellar and suprasellar regions with a high signal intensity on T1W imaging and a low signal intensity on T2W imaging with central necrosis, abutting the medial aspect of bilateral cavernous sinus. The lesion was compressing the inferior aspect of optic chiasm and anteriorly displacing the residual pituitary gland (arrow) 


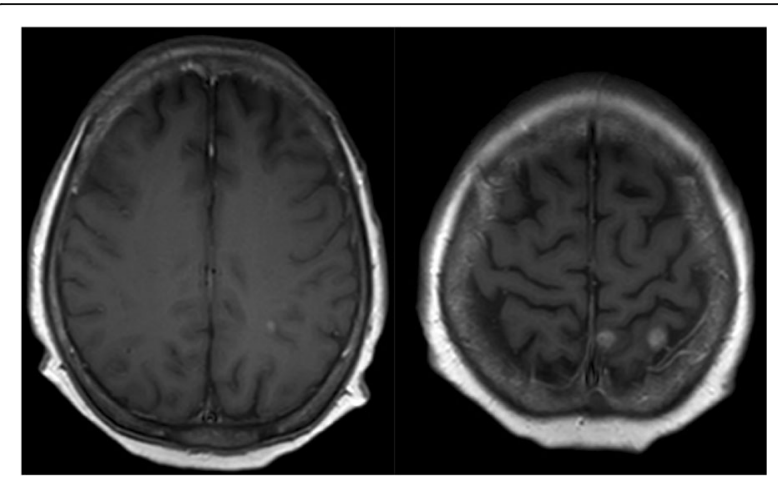

Fig. 3 Multiple small gadolinium enhancing lesions with adjacent vasogenic edema at the subcortical region of the left frontal and parietal areas shown on T1W axial images of the pituitary MRI

$2.2 \times 2.2 \mathrm{~cm}$ enhancing soft tissue mass at the proximal part of the right bronchus that supplies the medial segment of the right middle lung. This was causing atelectasis of the distal part of the medial segment of the right middle lung and diffuse centrilobular emphysema at both upper lobes without pleural effusion. The liver, spleen, kidneys, and adrenal glands appeared unremarkable. No osteolytic lesion of the ribs, spine, and other bony structures were seen (Fig. 5). The final diagnosis was advanced adenocarcinoma of the lung with pituitary metastasis associated with panhypopituitarism and central diabetes insipidus.

Palliative care for the advanced-stage lung cancer was offered to the patient. She received hormone replacement including desmopressin acetate $10 \mathrm{mcg}$ intranasal solution daily, oral prednisolone $5 \mathrm{mg}$ daily, and levothyroxine 75 mcg daily for central diabetes insipidus, secondary adrenal insufficiency, and central hypothyroidism, respectively.

Table 1 Initial hormonal evaluation

\begin{tabular}{|c|c|c|}
\hline Serum hormone (SI unit) & Result & Reference range \\
\hline IGF-1 (nmol/L) & 2.69 & $3.01-27.32$ \\
\hline Prolactin $(\mu \mathrm{g} / \mathrm{L})$ & 115 & $4.79-23.3$ \\
\hline Prolactin after 1:100 dilution $(\mu \mathrm{g} / \mathrm{L})$ & 81 & $4.79-23.3$ \\
\hline FSH (IU/L) & 1.39 & $25.8-134.8$ \\
\hline LH (IU/L) & $<0.1$ & $7.7-58.5$ \\
\hline FT4 (pmol/L) & 2.32 & $11.97-21.88$ \\
\hline TSH (mIU/L) & 19.07 & $0.27-4.2$ \\
\hline ACTH (ng/L) & 26.3 & $10.0-60.0$ \\
\hline Morning cortisol (nmol/L) & 138 & \\
\hline \multicolumn{3}{|c|}{ Cortisol after $250 \mu \mathrm{g} \mathrm{ACTH}$ stimulation test (nmol/L) } \\
\hline at $30 \mathrm{~min}$ & 237.3 & \\
\hline at $60 \mathrm{~min}$ & 306.2 & \\
\hline
\end{tabular}

IGF-1 Insulin-like growth factor 1, FSH Follicular stimulating hormone, LH Luteinizing hormone, FT4 Free thyroxine, TSH Thyroid-stimulating hormone, ACTH Adrenocorticotropic hormone
Two months later, she developed bilateral ophthalmoplegia and died 4 months after the diagnosis.

\section{Discussion and conclusions}

Pituitary metastases are usually detected in patients with advanced cancer and associated with widespread metastases, typically affecting elderly patients, especially those aged 60-70 years [17]. They often remain silent because co-existing metastases to the other organs cause death first [18]. According to one autopsy series, the prevalence of pituitary metastases was 0.14 to $28.1 \%$ among all brain metastases [19]. Latent pituitary metastases were found in $5 \%$ of patients with known primary malignancies, of which around two-thirds had macroscopically normal pituitary glands [4]. Malignant neoplasms of all tissue types from nearly all organs have been reported to metastasize to the pituitary. However, breast and lung are the most common sites of the primary tumor, accounting for 39.7 and $23.7 \%$ of all pituitary metastases, respectively [1]. A Swedish population-based study of metastatic sites of lung cancer reported that among primary lung cancers with pituitary metastasis, small cell lung cancer is the most common cell type, whereas adenocarcinoma and squamous cell carcinoma rarely metastasize to the pituitary gland but rather to the bones and respiratory system. Only a few cases of adenocarcinoma of the lung metastasized to the pituitary gland without other distant metastases [20]. Unlike typical cases, our patient had adenocarcinoma of the lung and the first manifestation was central diabetes insipidus and hypopituitarism secondary to pituitary metastasis without evidence of primary lung cancer or widespread metastasis.

The four pathways of metastases to the pituitary gland [21-23] include direct hematogenous spreading to the pituitary parenchyma or diaphragma sellae, spreading from a hypothalamo-hypophyseal or infundibulum metastasis through the portal vessels, extension from juxtasellar and skull base metastasis, and meningeal spreading through the suprasellar cistern.

Regarding the location of metastatic tumors in the pituitary, $84.6 \%$ were found at the posterior pituitary either alone or in combination with the anterior pituitary whereas only $15.4 \%$ were found at the anterior pituitary alone [1]. The posterior pituitary is a preferential site for metastases as it receives direct arterial blood supply from hypophyseal arteries whereas the blood supply to the anterior pituitary is mainly from the hypophyseal portal system, which is not arterial. Thus, the anterior pituitary is less predisposed to pituitary metastasis than the posterior portion $[1,23]$. Also, the posterior lobe has a larger contact area with dura mater $[4,5]$. Metastases to the anterior pituitary mostly originate from direct spreading of metastatic foci from the posterior pituitary [1] and associate with a larger area of the extending posterior pituitary lesion. In addition, the tumor in posterior 


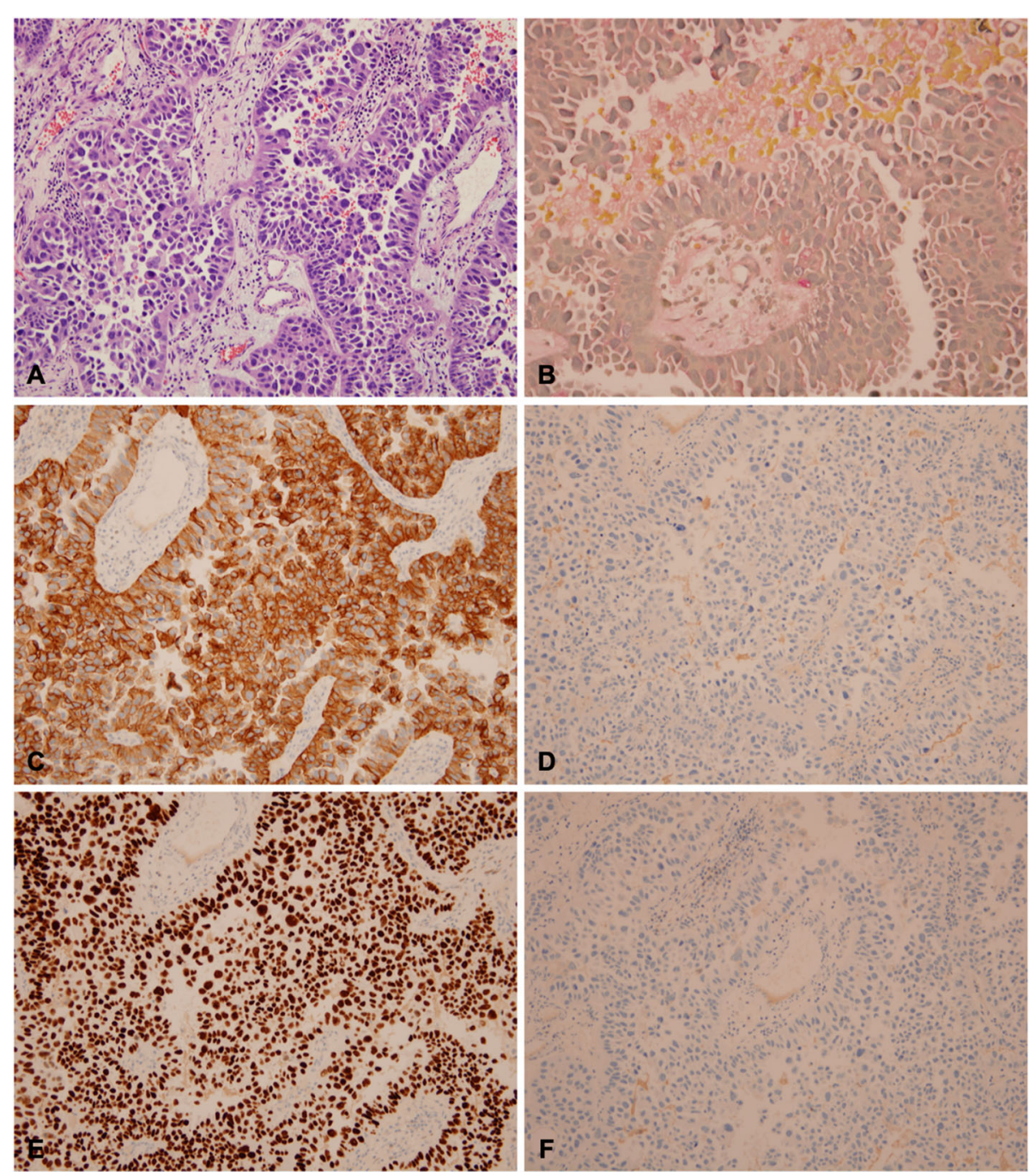

Fig. 4 Tumor resected from sellar mass composing of malignant epithelial cells with glandular formation (a hematoxylin-eosin, $\times 100)$ and intracellular mucin $(\mathbf{b} \times 200)$. Immunohistochemical study showed that tumor cells were immunoreactive for antibodies of cytokeratin 7 (c $\times 200)$ and TTF-1 (e $\times 200)$ but not cytokeratin $20(\mathbf{d} \times 200)$ and CDX-2 (f, $\times 200)$

lobe or stalk may potentially compromise a blood supply of the anterior lobe, resulting in ischemic infarct [4]. Thus, involvement of the anterior pituitary in our patient could be explained by the effect of large metastatic volume in the posterior pituitary as well as a damage to the vascular supply.

The majority of pituitary metastases are clinically silent. Symptomatic pituitary metastases were found in only $7 \%$ of cases [4], and it was rarely the first manifestation of the cancer [24]. Based on a literature review between 1994 and 2018, 26 cases of symptomatic pituitary metastasis as a presenting manifestation of silent primary malignancy were reported [7-15, 19, 25-35]. Nine of 26 cases had isolated pituitary metastasis [7-15], of which 5 had primary lung cancer [7, 9-12]. Among symptomatic patients, diabetes insipidus was the most common presenting symptom, found in $45.2 \%$ of all symptomatic pituitary metastases [1]. This resulted from the preference of metastases for the posterior pituitary $[36,37]$. Rarely, central diabetes insipidus is transient due to the regeneration of neurohypophyseal neuron fibers [16]. For anterior pituitary dysfunction, 23.6\% of the patients had one or more anterior pituitary hormone deficiency [1]. Corticotropin and thyrotropin deficiencies were the most common, followed by panhypopituitarism [10]. Approximately $6.3 \%$ had mild hyperprolactinemia, of which the serum prolactin levels were not higher than $149.2 \mathrm{ng} / \mathrm{mL}$ due to compression of the pituitary stalk [1].

The analysis of our patient's hormonal profiles showed panhypopituitarism with mild hyperprolactinemia and central diabetes insipidus, corresponding to her MRI findings that both the anterior and posterior pituitary glands were involved by metastasis. 


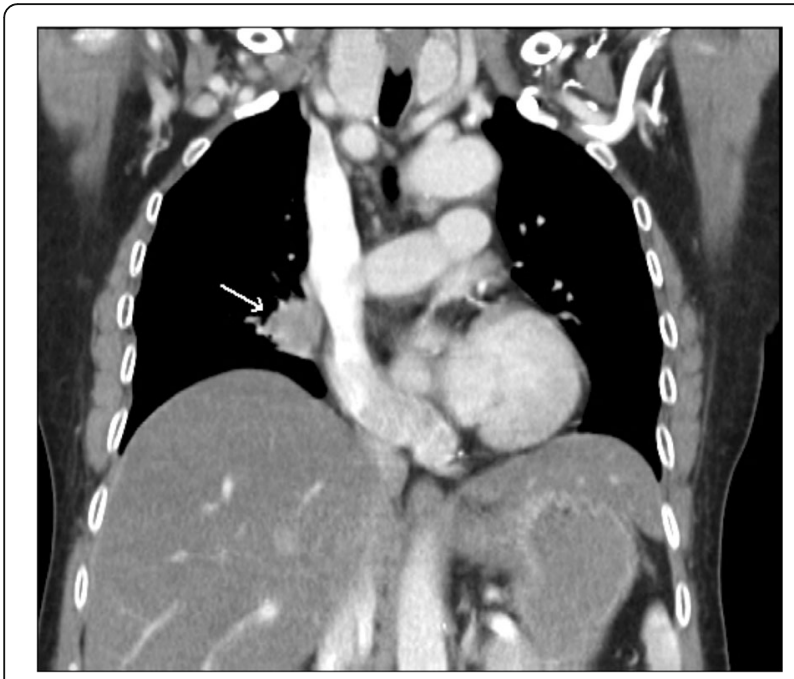

Fig. 5 CT chest with contrast revealing an enhancing soft tissue mass occupying the proximal part of bronchus supplying the medial segment of right middle lung (arrow)

Other symptoms of pituitary metastases included visual field deficits due to compression of the optic chiasm in $27.9 \%$ of cases, ophthalmoplegia caused by cranial nerve III, IV, or VI palsy in $21.6 \%$ of cases, headache and/or post-ocular pain in $15.8 \%$ of cases, and fatigue and/or general malaise in $7.9 \%$ of cases [1].

Some clues to raise clinical suspicion of pituitary metastasis in our patient were onset of diabetes insipidus at an older age, rapidly progressive weight loss, and fatigue. These were likely symptoms of tumor burden or hypopituitarism. Also, the recent onset of bitemporal hemianopia was a clinical clue of optic chiasm compression.

The radiographic findings of pituitary metastases are usually non-specific. In MRI studies, iso- or hypointensity signals on T1W imaging and hyperintensity on T2W imaging with homogeneous enhancement after gadolinium injection are the common findings. Imaging studies may be fruitful for distinguishing metastatic disease when the pituitary stalk is thickened, and invasion of the cavernous sinus along with sclerosis of the sella turcica are seen. Nonetheless, there were no such discriminative characteristics seen in our patient except for the presence of concomitant brain lesions with the same signal intensity as that of the suprasellar mass, which offered a diagnostic clue to metastatic pituitary tumor [38].

The prognosis of patients with pituitary metastasis is poor due to the aggressiveness of the primary malignancy. The mean survival after developing a pituitary metastasis is only 6 months as in our patient, and 1-year survival is less than $10 \%$ [3].

In conclusion, metastasis to the pituitary gland is a rare and life-threatening condition that results in poor prognostic outcomes. It is difficult to diagnose, especially in patients with previously undiagnosed primary cancer. Pituitary metastasis should be considered in elderly patients presenting with new-onset diabetes insipidus with or without anterior pituitary dysfunction. MRI findings of pituitary stalk thickening, invasion of cavernous sinus, sclerotic changes around the sella turcica, and coexistence of brain lesions are also important diagnostic clues.

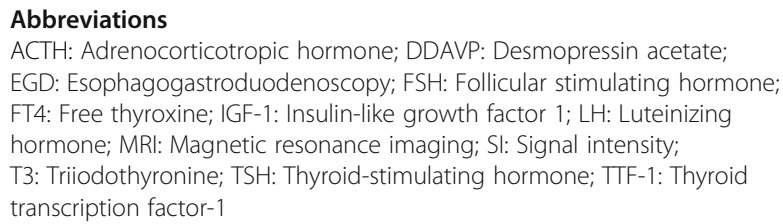

\section{Acknowledgments}

Not applicable

\section{Authors' contributions}

SSi, PV, PChu and SSr diagnosed the patient, provided endocrine treatment, and acquired clinical data. PChe provided pathological diagnosis. SSi and PV reviewed the literature, and the drafted manuscript. SSi and SSr revised and reviewed the manuscript for final publication. All of the authors read and approved the final manuscript.

\section{Funding}

No funding was obtained for this study.

\section{Availability of data and materials}

The data that support the findings of this case report are available from the corresponding author on reasonable request.

Ethics approval and consent to participate Not applicable

\section{Consent for publication}

Written informed consent for publication of this case report and accompanying images was obtained from the daughter of the patient after the patient's death. A copy of the consent form is available for review from the editor of this journal.

\section{Competing interests}

The authors declare that they have no competing interests.

\section{Author details}

'Division of Endocrinology and Metabolism, Department of Medicine, Faculty of Medicine Siriraj Hospital, Mahidol University, Bangkok, Thailand.

${ }^{2}$ Department of Pathology, Faculty of Medicine Siriraj Hospital, Mahidol University, Bangkok, Thailand.

Received: 7 May 2019 Accepted: 17 October 2019

Published online: 29 October 2019

\section{References}

1. Komninos J, Vlassopoulou V, Protopapa D, Korfias S, Kontogeorgos G, Sakas $\mathrm{DE}$, et al. Tumors metastatic to the pituitary gland: case report and literature review. J Clin Endocrinol Metab. 2004;89(2):574-80.

2. Fassett DR, Couldwell WT. Metastases to the pituitary gland. Neurosurg Focus. 2004;16(4):E8

3. Rajput R, Bhansali A, Dutta P, Gupta SK, Radotra BD, Bhadada S. Pituitary metastasis masquerading as non-functioning pituitary adenoma in a woman with adenocarcinoma lung. Pituitary. 2006;9(2):155-7.

4. Teears RJ, Silverman EM. Clinicopathologic review of 88 cases of carcinoma metastatic to the putuitary gland. Cancer. 1975;36(1):216-20.

5. Chiang MF, Brock M, Patt S. Pituitary metastases. Neurochirurgia. 1990; 33(4):127-31. 
6. Sioutos P, Yen V, Arbit E. Pituitary gland metastases. Ann Surg Oncol. 1996;3(1):94-9.

7. Camandaroba MP. Solitary non small cell lung cancer metastasis to the hypophysis: a case report. J Can Sci. Res. 2016;3(10). https://doi.org/10.4172/ 2576-1447.1000S1-010

8. Feghaly J, Astras G. Diagnosis and management of isolated pituitary metastasis from adenocarcinoma of unknown origin presenting as loss of libido. BMJ Case Rep. 2015;2015. https://doi.org/10.1136/bcr-2014-208735.

9. Harzallah L, Migaw H, Harzallah F, Kraiem C. Diabetes insipidus and panhypopituitarism revealing pituitary metastasis of small cell lung carcinoma: a case report. Ann Endocrinol. 2005;66(2 Pt 1):117-20.

10. Hsiao C-H, Wang C-Y, Chung M-T, Yang M-S. Diabetes insipidus due to pituitary metastasis in a woman with lung adenocarcinoma: a case report. Cen Eur J Med. 2011;6(4):475-9.

11. Ko JC, Yang PC, Huang TS, Yeh KH, Kuo SH, Luh KT. Panhypopituitarism caused by solitary parasellar metastasis from lung cancer. Chest. 1994;105(3):951-3.

12. Mansoor Q, Carey PE, Adams W. A rare ophthalmic presentation of pituitary metastases. BMJ Case Rep. 2012;2012. https://doi.org/10.1136/ bcr.11.2011.5145.

13. Moreno-Perez O, Peiro FM, Lopez P, Boix E, Meoro A, Serna-Candel C, et al. An isolated pituitary metastasis as presentation of a differentiated hepatocellular carcinoma mimicking a nonfunctioning macroadenoma. J Endocrinol Invest. 2007:30(5):428-33.

14. Shah N, Cavanagh Y, Shaaban H, Stein B, Shaikh SN, Kaswala DH, et al. An unusual initial presentation of hepatocellular carcinoma as a sellar mass. J Nat Sci Biol Med. 2015;6(2):471-4

15. Win K, Blocher N, Tester W, Serge G, Pomo L. Isolated pituitary metastasis from renal cell carcinoma in a horseshoe kidney. J Solid Tumors. 2018;8(1):37-41

16. Freda PU, Post KD. Differential diagnosis of sellar masses. Endocrinol Metab Clin North Am. 1999;28(1):81-117 vi.

17. Nelson PB, Robinson AG, Martinez AJ. Metastatic tumor of the pituitary gland. Neurosurgery. 1987;21(6):941-4.

18. Matsuda R, Chiba E, Kawana I, Kihara M, Tomiyama M, Ebira H, et al. Central diabetes insipidus caused by pituitary metastasis of lung cancer. Intern Med (Tokyo, Japan). 1995;34(9):913-8.

19. McCormick PC, Post KD, Kandji AD, Hays AP. Metastatic carcinoma to the pituitary gland. Br J Neurosurg. 1989;3(1):71-9.

20. Riihimaki M, Hemminki A, Fallah $M$, Thomsen $H$, Sundquist $K$, Sundquist J, et al. Metastatic sites and survival in lung cancer. Lung Cancer (Amsterdam, Netherlands). 2014;86(1):78-84.

21. Max MB, Deck MD, Rottenberg DA. Pituitary metastasis: incidence in cancer patients and clinical differentiation from pituitary adenoma. Neurology. 1981;31(8):998-1002.

22. Morita A, Meyer FB, Laws ER Jr. Symptomatic pituitary metastases. J Neurosurg. 1998;89(1):69-73.

23. Zager EL, Hedley-Whyte ET. Metastasis within a pituitary adenoma presenting with bilateral abducens palsies: case report and review of the literature. Neurosurgery. 1987;21(3):383-6.

24. Pinet C, Raholimina V, Ferri RM, Kleisbauer JP. Panhypopituitarism secondary to pituitary metastases. Presse Med (Paris, France: 1983). 2000;29(1):17-8.

25. Aung TH, Po YC, Wong WK. Hepatocellular carcinoma with metastasis to the skull base, pituitary gland, sphenoid sinus, and cavernous sinus. Hong Kong Med J. 2002;8(1):48-51.

26. Dutta P, Bhansali A, Shah VN, Walia R, Bhadada SK, Paramjeet S, et al. Pituitary metastasis as a presenting manifestation of silent systemic malignancy: a retrospective analysis of four cases. Indian J Endocrinol Metab. 2011;15(Suppl 3):S242-5.

27. Fridley J, Adams G, Rao V, Patel A, Humphries W, Goodman C, et al. Small cell lung cancer metastasis in the pituitary gland presenting with seizures and headache. J Clin Neurosci. 2011;18(3):420-2.

28. Leaes CG, Silva LA, Pereira-Lima JF, Kramer J, Oliveira MC. Pituitary metastasis from adenocarcinoma. Arq Neuropsiquiatr. 2011;69(5):845-6.

29. Lin D, Griffith B, Patel S, Rock J, Marin H. Pituitary metastasis from lung carcinoma presenting as a pituitary adenoma. Appl Radiol. 2018:47(7):34-6

30. Marmouch H, Arfa S, Mohamed SC, Slim T, Khochtali I. An acute adrenal insufficiency revealing pituitary metastases of lung cancer in an elderly patient. Pan Afr Med J. 2016;23:34.

31. Poursadegh Fard M, Borhani Haghighi A, Bagheri MH. Breast cancer metastasis to pituitary infandibulum. Iran J Med Sci. 2011;36(2):141-4.
32. Samaras I, Tsapakidis T, Maragouli E, Sogka E, Litos I, Tolia M, et al Metastatic breast carcinoma to the pituitary gland that presented as diabetes insipidus: A case report. J Cancer Prev Curr Res. 2017;8(2):00273.

33. Thewjitcharoen $Y$, Shuangshoti S, Lerdlum S, Siwanuwatn R, Sunthornyothin $S$. Colorectal cancer manifesting with metastasis to prolactinoma: report of a case involving symptoms mimicking pituitary apoplexy. Intern Med (Tokyo, Japan). 2014;53(17):1965-9.

34. Woo P, Li R, Sk Chan T, Kh Pang P, Chan Y, Chan KY, et al. Symptomatic metastasis to the pituitary gland: a report of three cases and review of the literature; 2015. p. 1-4.

35. Yaylalı G, Topsakal S, Değirmencioğlu S, Fenkçi S. Pituitary metastases of lung cancer presenting with hypopituitarism. In: Presented at 19th European Congress of Endocrinology, Lisbon, Portugal Endocrine Abstracts EP971; 2017. p. 49

36. Bell CD, Kovacs K, Horvath E, Smythe H, Asa S. Papillary carcinoma of thyroid metastatic to the pituitary gland. Arch Pathol Lab Med. 2001; 125(7):935-8.

37. Lau G, Tan SY, Chiang G, Poh WT. Bronchioloalveolar carcinoma with metastasis to the pituitary gland: a case report. J Clin Pathol. 1998; 51(12):931-4.

38. Schubiger $\mathrm{O}$, Haller D. Metastases to the pituitary--hypothalamic axis. an MR study of 7 symptomatic patients. Neuroradiology. 1992;34(2):131-4.

\section{Publisher's Note}

Springer Nature remains neutral with regard to jurisdictional claims in published maps and institutional affiliations.

\section{Ready to submit your research? Choose BMC and benefit from:}

- fast, convenient online submission

- thorough peer review by experienced researchers in your field

- rapid publication on acceptance

- support for research data, including large and complex data types

- gold Open Access which fosters wider collaboration and increased citations

- maximum visibility for your research: over $100 \mathrm{M}$ website views per year

At $\mathrm{BMC}$, research is always in progress.

Learn more biomedcentral.com/submissions 